\title{
Extraction and Characterisation of Cellulose Nanocrystals from Pineapple Peel
}

\author{
Ana Raquel Madureira ${ }^{a^{*}}$, TuĞba Atatoprak ${ }^{\mathrm{a}}$, Duygu ÇabuK ${ }^{\mathrm{a}}$, Flávia Sousa $^{\mathrm{b}}$, \\ Robert C. Pullar ${ }^{\mathrm{c}}$, And Manuela Pintado ${ }^{\mathrm{a}}$ \\ ${ }^{\text {a }}$ Centro de Biotecnologia e Química Fina, Escola Superior de Biotecnologia, Universidade Católica \\ Portuguesa, Rua Dr. António Bernardino de Almeida, 4200-072 Porto, Portugal \\ b CICS - Department of Pharmaceutical Sciences, Institute of Health Sciences-North, CESPU, Rua Central de \\ Gandra, 1317, 4585-116 Gandra, Portugal \\ ${ }^{c}$ Dept. Engenharia de Materiais e Cerâmica / CICECO - Aveiro Institute of Materials, Universidade de \\ Aveiro, Campus Universitário de Santiago, 3810-193 Aveiro, Portugal \\ ${ }^{*}$ Corresponding author \\ rmadureira@porto.ucp.pt \\ TEL: +351-225580044 \\ FAX: $+351-225580000$
}

Received: 26 October 2016; Published online: 18 April 2018

Invited paper from the $4^{\text {th }}$ International ISEKI Food Conference - ISEKI_Food 2016 - Bridging Training and Research for Industry and the Wider Community - Responsible Research and Innovation in the Food Value

\begin{abstract}
The potential of pineapple peel as a source of cellulose nanocrystals was evaluated. Peels skin from fresh-cut fruit was used as raw material. These residues were purified to remove pigments, lipids and hemicellulose, and a bleaching process for delignification was carried out for 4-6 h. All resulting products were characterised for their lignin, hemicellulose, cellulose and ash contents using standard techniques. Dry matter at the end was low (ca. 50\%) compared with the raw material (ca. 90\%). The process applied resulted in ca. $20 \%(\mathrm{~m} / \mathrm{m})$ of purified cellulose (ca. $80 \%$ purity), with ineligible levels of lignin and hemicellulose present, especially when using $6 \mathrm{~h}$ of bleaching. The purified cellulose was subject to acid hydrolysis for nanocrystal extraction with two testing times, 30 and 60 minutes. These cellulose nanocrystals had small sizes $(<1000 \mathrm{~nm})$, with high variability and negative zeta potential values. The time of extraction did not affect the nanocrystals' chemical and physical properties. The use of $6 \mathrm{~h}$ of bleaching treatment during purification was shown to be more effective than $4 \mathrm{~h}$. Pineapple peel was demonstrated to be a good source of cellulose for the production of cellulose nanocrystals.
\end{abstract}

Keywords: Cellulose; CNC; Pineapple peels

\section{Introduction}

In the last decade, there is a great deal of research focusing on the use of cellulosic-rich wastes. Cellulose fibre is the most abundant renewable material, constitutes the major component of plant fibres, and is a natural hydrophilic polymer. Plant/vegetable fibres consist of cellulose, hemicellulose and lignin. Hemicellulose is a branched multiple polysaccharide polymer, composed of different types of sugars including glucose, xylose, galactose, arabinose and mannose. Lignin is a highly cross-linked phenolic polymer. Both hemicellulose and lignin are amorphous polymers, whereas cellulose is a semi-crystalline polymer. There are two types of linkages between hemicellulose groups and lignin. One is an ester- 


\section{Nomenclature}

CNC Cellulose Nanocrystal

PP Pineapple Peel

TPP Treated Pineapple Peel

TPP4 Treated Pineapple Peel with a bleaching treatment of 4 hours

TPP6 Treated Pineapple Peel with a bleach- ing treatment of 6 hours

PS Particle Size

PI Polydispersity Index

ZP Zeta Potential

NP Nanoparticles type bond between the hydroxyl of lignin and the carboxyl of uronic acid in hemicellulose. This linkage is sensitive to alkali solutions. Hence, starting from raw fibres, an alkali treatment can be applied to hydrolyse and remove the hemicellulose, soluble mineral salts and other components (Deepa et al., 2011). The second linkage is of an ether-type, and is formed between the hydroxyls of lignin and those of carbohydrates. Other linkage types are insensitive to alkali solutions, but an acid hydrolysis can be applied to disrupt these amorphous domains. This treatment releases individual rod-like rigid nanocrystals, named cellulose nanocrystals (CNCs) (Aspler et al., 2013), and introduces negative charges to their surface due to the formation of sulphate ester groups. Cellulose nanocrystals possess high mechanical strength, high surface area and aspect ratio, non-toxicity, biocompatibility and biodegradability, making them an excellent candidate for pharmaceutical applications (Lin \& Dufresne, 2014). Because of their properties, CNCs could be used for numerous applications, such as the preparation of composite materials, regenerative medicine and drug delivery (Qiu \& $\mathrm{Hu}, 2013)$.

The majority of the studies of extraction of CNCs from food industry wastes and natural sources are very recent, owing to the interest generated in such systems. Studies were made on the extraction from wood, sisal, coconut husks, agave fibres, bananas, rice husks, soy hulls, mango seeds, sweet potato residue, garlic skins, pineapple leaves, mengkuang and capim mombaça (Cherian et al., 2010; Deepa et al., 2011; Flauzino Neto, Silverio, Dantas, \& Pasquini, 2013; Henrique, Silvério, Neto, \& Pasquini, 2013; Johar, Ahmad, \& Dufresne, 2012; Prozil, Evtuguin, Silva, \& Lopes, 2014).

However, pineapple processing residues have not been explored until now, and this fruit is one of the most important commercial fruits of the world. It is a typical tropical fruit, with a total global annual production between 16 and 19 million tonnes. Generally, pineapple is consumed as fresh fruit, or is processed into salads, fruit cocktail and jam/conserves, or canned. During pineapple fruit processing, the wastes (peel and stems mainly), ca. $50 \%(\mathrm{w} / \mathrm{w})$ of total pineapple weight, are removed and discarded. In fact, pineapple peel consists of cellulose, hemicellulose, lignin and pectin, and represents the largest portion of pineapple wastes $(30-42 \%$, w/w) $(\mathrm{Hu}$, Wang, \& Huang, 2013). The composition is ca. $42 \%$ fibre, ca. $9 \%$ protein and $1.5 \%$ lipids.

Hence, the aim of this study was to evaluate the potential of using pineapple peel residues as a source of CNCs, and to characterise them in terms of physical properties.

\section{Materials and Methods}

\subsection{Purification of pineapple residues}

Pineapple residues were provided from a freshcut fruit processing company. The peel was immediately frozen after processing procedures 
(Fig. 1a), while still at the company production line. Initially, the pineapple peels (PP) were dried and milled (Fig. 1b). They were treated with a $2 \%(\mathrm{w} / \mathrm{w}) \mathrm{NaOH}$ solution for $4 \mathrm{~h}$ at 100 ${ }^{\circ} \mathrm{C}$ under mechanical stirring, and then washed several times with deionised water until the alkali was completely removed, and finally dried at $50{ }^{\circ} \mathrm{C}$ for $12 \mathrm{~h}$ in an air-circulating oven (Fig. 1c). After this treatment, the resulting fibres were bleached with a solution made up of equal parts (v:v) of acetate buffer $(27 \mathrm{~g} \mathrm{NaOH}$ and 75 $\mathrm{mL}$ glacial acetic acid, diluted to $1 \mathrm{~L}$ with distilled water) and aqueous sodium chlorite (1.7 wt\% $\mathrm{NaClO}_{2}$ in water). This bleaching treatment was performed at $80^{\circ} \mathrm{C}$ for $4 \mathrm{~h}$ or $6 \mathrm{~h}$ (Fig. $1 \mathrm{~d} \& \mathrm{e})$. The bleached fibres were washed repeatedly in distilled water, until their $\mathrm{pH}$ became neutral, and subsequently dried at $50{ }^{\circ} \mathrm{C}$ for 12 $\mathrm{h}$ in an air-circulating oven. The material which resulted after this purification was the treated pineapple peel (TPP), and this was subsequently bleached for $4 \mathrm{~h}$ (TPP4) and $6 \mathrm{~h}$ (TPP6).

\subsection{Extraction of cellulose nanocrystals (CNCs)}

After the chemical treatment described previously, TPP4 and TTP6 dried material was milled with a blender, and the nanocrystals extracted by acid hydrolysis. The hydrolysis was performed at $50{ }^{\circ} \mathrm{C}$, for either $30 \mathrm{~min}$ or $60 \mathrm{~min}$, under vigorous and constant stirring. For each gram of TPP, $20 \mathrm{~mL}$ of a solution of $\mathrm{H}_{2} \mathrm{SO}_{4} 64 \%$ $(\mathrm{w} / \mathrm{w})$ was used. Immediately following the hydrolysis, the suspension was diluted 10-fold with cold water to stop the hydrolysis reaction, and centrifuged twice for $10 \mathrm{~min}$ at $7000 \mathrm{rpm}$ to remove the excess acid. The precipitate was then dialysed with tap water to remove non-reactive sulphate groups, salts and soluble sugars, until a neutral $\mathrm{pH}$ was achieved (5-7 days). Subsequently, the resulting suspension of the dialysis process was sonicated for 5 min at $70 \%$ intensity in a VCX 130 ultrasonicator (Sonics \& Materials, Newtown, USA), with sample tubes immersed in an ice bath to prevent heating. The colloidal suspension was stored in a refrigerator at $4{ }^{\circ} \mathrm{C}$, with the addition of some drops of chloroform to avoid any bacterial growth until the freeze-drying pro-

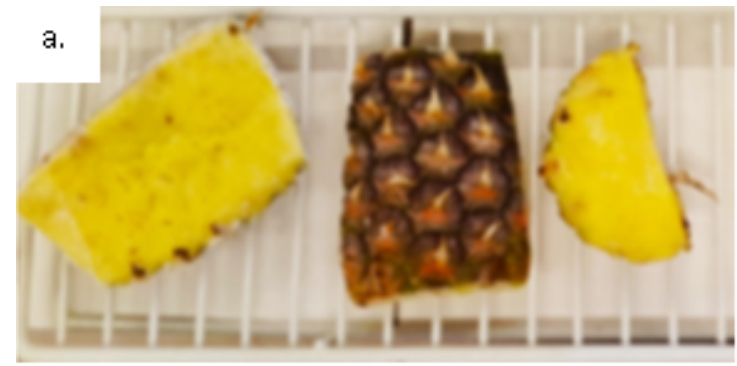

b.

c.
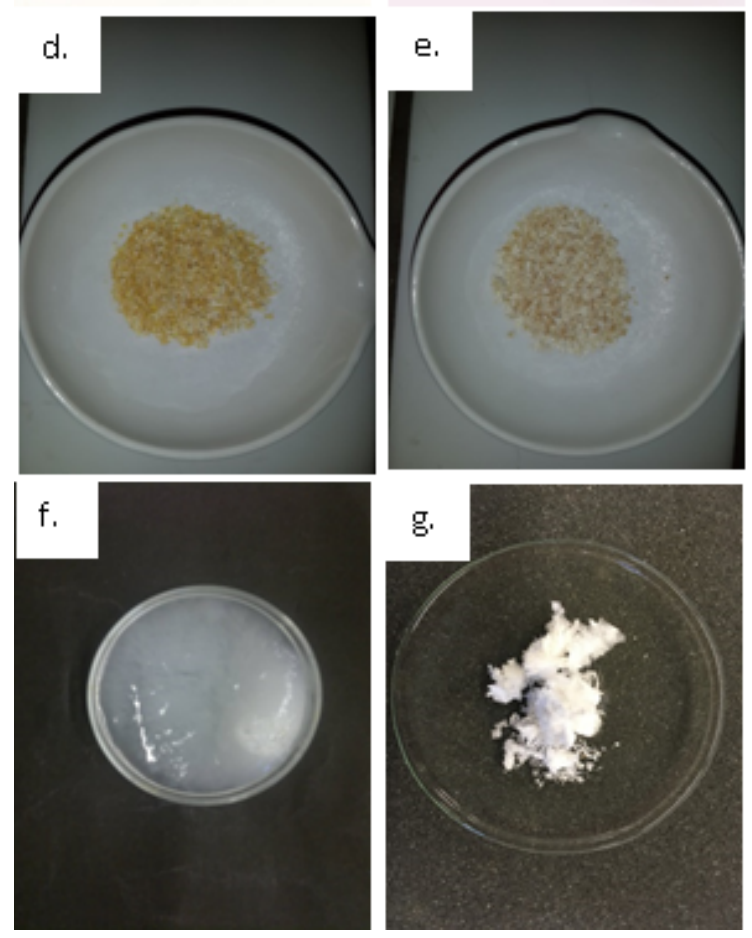

Figure 1: Images of fresh pineapple peel residues (a), dried and milled pineapple peel PP (b), after alkali drying and milling treatments (c), TPP4 (after $4 \mathrm{~h}$ bleaching), drying and milling treatments (d), TPP6 (after 6h bleaching), drying and milling treatments (e), CNC30 colloidal and dialysed suspension after 30 min acid hydrolysis (f), and lyophilised CNC30 (g). 
cess. The freeze-drying process was performed using a Vacuum Freeze Drier (Model FT33, Armfield, UK), under a vacuum pressure of 100 millitorr; the temperature in the freezing chamber was $-46{ }^{\circ} \mathrm{C}$, and the temperature in the sample chamber was $15{ }^{\circ} \mathrm{C}$. The cellulose nanocrystals were labelled as CNC30 or CNC60, depending on the time of extraction by hydrolysis (30 and 60 minutes, respectively).

\subsection{Product chemical characterisation}

The chemical composition of the dried PP and TPP was measured as follows. The lignin content was determined according to the standard method of the Technical Association of Pulp and Paper Industry TAPPI T222 om-88. The holocellulose ( $\alpha$-cellulose + hemicellulose $)$ content was estimated by the acid chlorite method (Browning, 1967). The $\alpha$-cellulose content was determined by treating the holocellulose with a potassium hydroxide solution (Browning, 1967). The hemicellulose $\%$ was determined by subtracting the $\alpha$-cellulose content from the holocellulose. An average of three replicates was calculated for each sample.

\subsection{Fourier transform infrared spectroscopy (FTIR)}

An IRPrestige-21 infrared spectrophotometer (Shimadzu, Japan) was used to obtain spectra for PP, TPP and CNC30. The KBr disk (ultrathin pellets) method was used to measure the IR spectra. Samples were ground and mixed with $\mathrm{KBr}$ (sample/KBr ratio =1/100) to prepare discs. The experiments were carried out using the wavenumber range of $500-4000 \mathrm{~cm}^{-1}$, with a resolution of $4 \mathrm{~cm}^{-1}$ and a total of 32 scans for each sample.

\subsection{Particle size and charge measurements by dynamic light scattering (DLS)}

Particle size (PS), polidispersity index (PI) and zeta potential (ZP) were measured using dy- namic light scattering (DLS) with a ZetaSizer NanoZSP (Malvern, UK). Particle sizes were measured by taking into account the first order result from a DLS experiment as an intensity distribution of PS. The intensity distribution was weighted according to the scattering intensity of each particle fraction or family. Data was validated only if the cumulants fit error was $<0.005$. Zeta potential was measured using Laser Doppler Anemometry $(L D A)$. All analyses were carried out with an angle of $90^{\circ}$ at $25^{\circ} \mathrm{C}$.

\subsection{X-ray diffraction (XRD)}

$\mathrm{X}$-ray diffraction (XRD) was carried out using a Rigaku Geigerflex D/max Series diffractometer with $\mathrm{Cu} \mathrm{K} \alpha$ radiation, between $20-70^{\circ}$, with a $2 \theta$ step size of $0.02^{\circ}$ and a time of $10 \mathrm{~s}$ per step. The crystallite size was estimated from the FWHM (full width at half maximum) value of the $100 \%$ cellulose peak at $22.3^{\circ}$, using the Scherrer equation:

$$
D=\frac{K \lambda}{h_{1 / 2} \cos \theta}
$$

where $\mathrm{D}=$ average size of the crystallites, $\mathrm{K}$ $=$ Scherrer constant (0.94 for spherical crystals), $\lambda=$ wavelength of radiation $(1.54056 \AA), \mathrm{h}_{1 / 2}=$ FWHM, and $\theta=$ Bragg angle (the peak position $=2 \theta)$.

\subsection{Scanning Electron Microscopy (SEM)}

Morphology of PP, TPP and CNC was evaluated by Scanning Electron Microscopy (SEM) using a JEOL-5600 Lv microscope (Tokyo, Japan). Briefly, a small amount of freeze-dried sample was placed on a metallic stub with carbon tape and coated with gold/palladium using a Sputter Coater (Polaron, Bad Schwalbach, Germany). SEM was operated at the high vacuum mode, with a potential of $15-20 \mathrm{kV}$. All analyses were performed at room temperature $\left(20^{\circ} \mathrm{C}\right)$. 


\section{Results and Discussion}

\subsection{Extraction process and physical properties of CNC}

Pineapple peel was obtained from a local freshcut fruit production company which is dedicated to the processing of ready-to-eat fruit, such as melon, mango and pineapple. The dried and milled pineapple peel (PP) contains several components (Fig. 1b), such as pigments, proteins and lipids. In Table 1, the chemical composition of each product generated is depicted. In terms of dry matter, a decrease of ca. $90 \%$ to $50 \%$ occurred after the bleaching process. This is a consequence of the occurrence of the lost of cellulose during the process, since no increase on cellulose content occurs after bleaching treatment. These results can be related to the breakdown of cellulose chains during bleaching and the loss of material during the filtering processes and mass transfer.

Lignin is the major component of the $\mathrm{PP}$ at ca. $29 \%$, followed by cellulose (ca. 17\%) and hemicellulose (ca. 16\%) (Table 1). These values accord with those found by a few other authors that characterized pineapple peel (Raji, Jibril, Misau, \& Danjuma, 2012; Thirawan, Karnnasuta, \& Srinorakutara, 2017). In the samples purified by the alkali process, a bleaching was performed during two times, 4 and $6 \mathrm{~h}$ (TPP4 and TPP6). With the bleaching process, the delignification of the samples is supposed to occur (Cherian et al., 2010). For the two times of study, a high decrease in lignin was detected, which proved the efficiency of delignification treatment. The hemicellulose $\%$ was determined by subtracting the $\alpha$-cellulose content from the holocellulose. Hemicelullose \% decreased, as is supposed to happen with the first alkaline treatment. Holocellulose present in the bleached samples only contained cellulose and very low hemicelluloses' content, ca. $54 \%$ of $\alpha$-cellulose and increased to more than $80 \%$ of cellulose after bleaching (data not shown). When calculating the $\%$ of cellulose in the initial samples' masses, the values were shown to be maintained or slightly increased (Table 1). Nevertheless, the TPP products were used to extract the cellulose nanocrystals. At the end of hydrolysis, samples were dialyzed, and a gelly and alkaline suspension was obtained as shown in Fig. 1f.

The colloidal suspensions of TPP4 and TPP6 were analysed by DLS to determine the CNC particle size in suspension and charge (Table 2). The sizes obtained were high since crystals' length is also measured, not only the width, using a DLS scatter that is dynamic, and agglomeration may occur in solution. Nevertheless, smaller CNCs were obtained for TPP6 than for TPP4.

The polydispersity index (PI) indicates the variation in the distribution of the particle size. Aa high polydispersity shows the existence of particle families with different sizes, which may mean the occurrence of aggregation (Hanaor, Michelazzi, Leonelli, \& Sorrell, 2012). In general, all samples showed PI values much higher than 0.3 , which indicates a polydisperse distribution of CNCs. On the other hand, zeta potential (ZP) can give us an indication of whether repulsion between adjacent, similarly charged particles in dispersion will occur or not. When $\mathrm{ZP}$ is high (whether they are positive or negative values) means stability between the particles, whereas when the potential is low, particles tend to coagulate/flocculate as attraction exceeds repulsion in the dispersion. The $\mathrm{ZP}$ values where ca. $30 \mathrm{mV}$ in the CNCs extracted from TPP4, which means a moderate stability. In the case of the CNCs extracted from TPP6, this value decreased but is still moderate. In both cases, the values are negative, which is a result of the acid hydrolysis, in which sulphuric acid removed the amorphous regions in the cellulose fibres, leaving only the highly ordered crystalline regions intact, resulting in negatively charged, sulphonated nanoparticles. Due to the relatively low surface charge, this method required ultrasonication to disperse and stabilize the CNC suspension.

The colloidal suspensions with the lowest sizes, i.e. those originating from TPP6, were freezedried and a white and light powder was obtained as shown in Fig. 1g. 
CNC from pineapple peels $\mid 29$

Table 1: Chemical characterisation in $\%(\mathrm{w} / \mathrm{w})$ (means $\pm \mathrm{SD})$ of the products obtained during samples processing

\begin{tabular}{ccccc}
\hline Samples & Lignin & Cellulose & Hemicellulose & Ash \\
\hline PP & $28.9 \pm 0.390$ & $16.9 \pm 2.02$ & $15.8 \pm 2.02$ & $3.92 \pm 0.721$ \\
TPP4 & $3.40 \pm 0.103$ & $21.8 \pm 0.793$ & $3.91 \pm 0.983$ & $2.48 \pm 0.201$ \\
TPP6 & $2.48 \pm 0.041$ & $21.0 \pm 1.23$ & $2.79 \pm 1.03$ & $2.00 \pm 0.510$ \\
\hline
\end{tabular}

PP-Pineapple peels residues; TPP-Treated and bleached residues $4 \mathrm{~h}(\mathrm{TPP} 4)$ and $6 \mathrm{~h}$ (TPP6)

Table 2: Chemical characterisation in $\%(\mathrm{w} / \mathrm{w})($ means $\pm \mathrm{SD})$ of the products obtained during samples processing.

\begin{tabular}{ccccc}
\hline $\begin{array}{c}\text { Purification time } \\
(\mathbf{h})\end{array}$ & $\begin{array}{c}\text { CNC } \\
\text { (hydrolysis time) }\end{array}$ & $\begin{array}{c}\text { Particle size } \\
\mathbf{( n m )}\end{array}$ & $\begin{array}{c}\text { Polidispersity } \\
\text { index }\end{array}$ & $\begin{array}{c}\text { Zeta potential } \\
\mathbf{( m v})\end{array}$ \\
\hline \multirow{2}{*}{ TPP4 } & 30 & $2291 \pm 1556$ & $0.891 \pm 0.0792$ & $-29.8 \pm 3.83$ \\
& 60 & $970.1 \pm 242.8$ & $0.859 \pm 0.1297$ & $-32.7 \pm 1.32$ \\
TPP6 & 30 & $657.8 \pm 188.7$ & $0.611 \pm 0.1319$ & $-13.8 \pm 1.35$ \\
& 60 & $1455 \pm 91.15$ & $1.000 \pm 0.0381$ & $-15.3 \pm 3.99$ \\
\hline
\end{tabular}

TPP4-Treated pineapple residues after $4 \mathrm{~h}$ bleaching; TPP6-Treated pineapple residues after $6 \mathrm{~h}$ bleaching

\section{$3.2 \quad$ FTIR spectra}

The powders of the PP, TPP4, TPP6, and CNCs obtained from TPP6, were analysed by FTIR and compared (Fig. 2). The presence of peaks $\mathbf{1}$ and 4 at 3310 and $1640 \mathrm{~cm}^{-1}$, respectively, in all samples shows that during the purification, cellulose is present and was not removed during the purification and CNC extraction processes (Sheltami, Abdullah, Ahmad, Dufresne, \& Kargarzadeh, 2012; Sun, Xu, Sun, Fowler, \& Baird, 2005). Peak 2 at $2900 \mathrm{~cm}^{-1}$ is from the C-H stretching vibration, is also present in all samples as expected, and was observed in other similar samples (Alemdar \& Sain, 2008; Sheltami et al., 2012). Peak 3 at $1700 \mathrm{~cm}^{-1}$ originates from the acetyl and ester groups in hemicellulose, or carboxylic acid groups in the ferulic and p-coumeric components of lignin. The existence of this peak shoulder was also reported in other works with wheat straw, rice husks and soy hulls (Alemdar \& Sain, 2008; Flauzino Neto et al., 2013; Sun et al., 2005). It should disappear with extraction, since hemicellulose is removed from $\mathrm{PP}$ with the $\mathrm{pu}-$ rification process. Indeed, this peak is more pronounced in PP than TPP4 and TPP6, and disappears in the CNC spectra. Peaks 6 and 7 at
1060 and $897 \mathrm{~cm}^{-1}$, respectively, correspond to the cellulose $\mathrm{C}-\mathrm{O}$ stretching and $\mathrm{C}-\mathrm{H}$ vibrations of cellulose, and appeared in all of the spectra, growing with extraction (Alemdar \& Sain, 2008; Sheltami et al., 2012). Peak 5 at $1205 \mathrm{~cm}^{-1}$ is only present in the CNC spectra, and it is not common to see in other CNCs extracted from lignocellulosic materials. It can be attributed to the S-O vibration, due to the esterification reaction, as reported in soy hulls (Flauzino Neto et al., 2013) (Lu, Gui, Zheng, \& Liu, 2013; Lu \& Hsieh, 2012).

\subsection{X-ray diffraction measurements}

The CNCs obtained from the two purification treatments, TPP4 and TPP6, were evaluated regarding their degree of crystallinity. Both intraand intermolecular hydrogen bonding occurs in cellulose via hydroxyl groups, which results in various ordered crystalline arrangements. The x-ray diffractograms obtained (Fig. 3) are typical of cellulose I, the more widespread crystalline form of the 4 existent cellulose polymorphs, with well-defined crystalline peaks around $22^{\circ}$ and $35^{\circ}$ (Klemm, Heublein, Fink, \& Bohn, 2005). The 
30 Madureira et al.

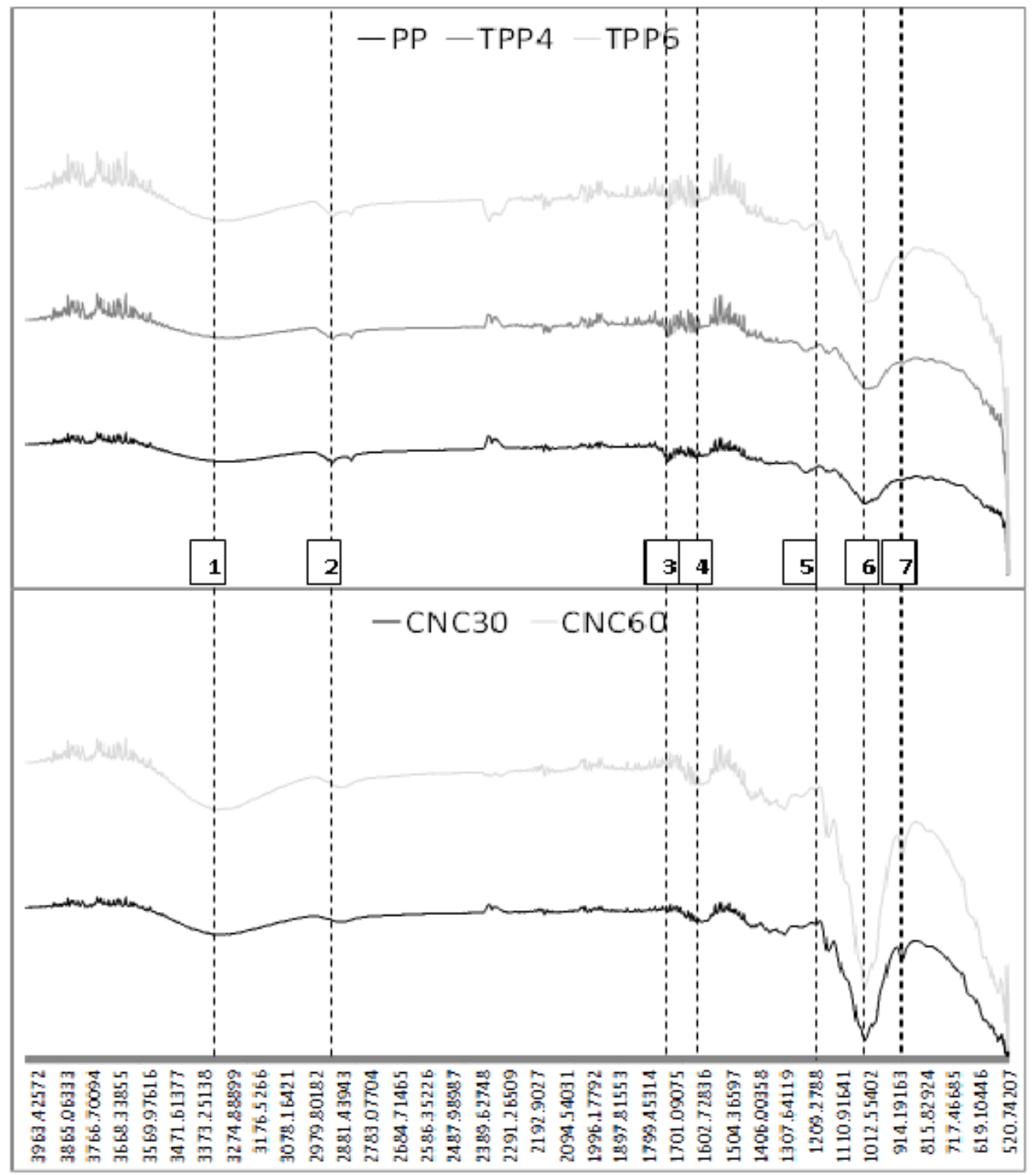

Figure 2: FTIR spectra of dried and milled pineapple peel (PP), after 4h bleaching, drying and milling treatments (TPP4) or after $6 \mathrm{~h}$ bleaching (TPP6) and cellulose nanocrystals (CNCs) obtained from 6 $\mathrm{h}$ of purification (TPP6) and after $30 \mathrm{~min}$ (CNC30) and $60 \mathrm{~min}$ (CNC60) of acid hydrolysis. 1- 3310 $\mathrm{cm}^{-} 1 ; 2-2900 \mathrm{~cm}^{-} 1 ; 3-1742 \mathrm{~cm}^{-} 1 ; 4-1640 \mathrm{~cm}^{-} 1 ; 5-1307 \mathrm{~cm}^{-} 1 ; 6-1060 \mathrm{~cm}^{-} 1 ; 7-897 \mathrm{~cm}^{-} 1$. 
CNC from pineapple peels $\mid 31$

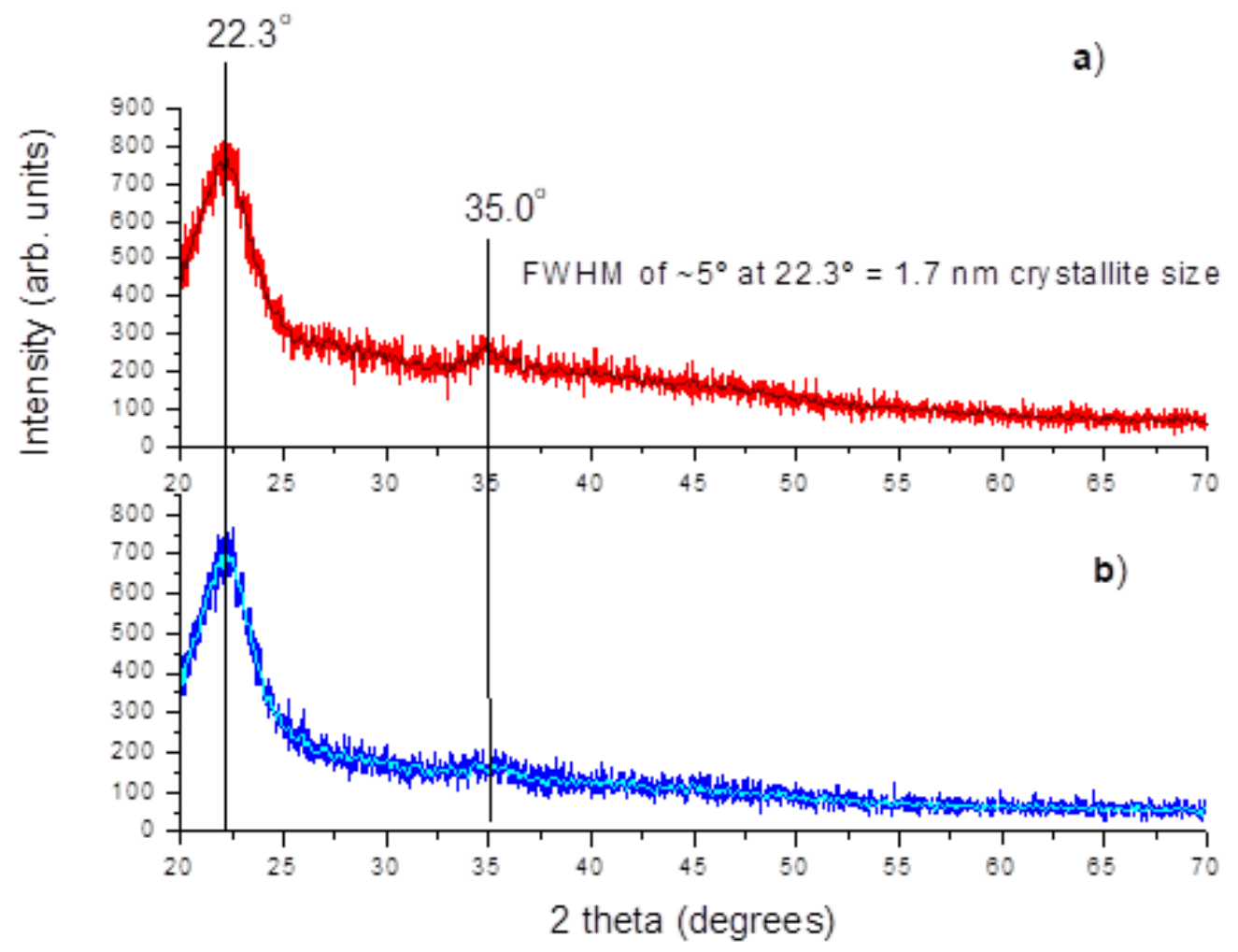

Figure 3: X-ray diffraction patterns of CNCs obtained from hydrolysis for 30 min of TPP6 (a) and TPP4 (b)

major peak, which is related to the crystalline structure of cellulose I, was seen for all samples at $22.3^{\circ}$, with a much smaller peak at $35.0^{\circ}$, and both indicate a poorly crystalline material, made of nanoscale crystals. The background "hump" around $20-30^{\circ}$ also indicates the presence of some amorphous material. The peaks are slightly more pronounced in the CNC obtained from TPP6, which again shows the importance of using a higher bleaching time during purification to better remove lignin and hemicellulose. The average cross-sectional dimension of the elementary cellulose crystallites was estimated from their X-ray diffractograms by applying the Scherrer equation, as described in Section 2. The Scherrer equation is unreliable for dimensions lower than $100 \mathrm{~nm}$, as the broadening becomes excessive, but it can still be used to get a very approximate estimate of the average crystallite size. For both samples in Fig. 3, with a FWHM of $\sim 5^{\circ}$, the value for the crystallite size was found to be only $1.7 \mathrm{~nm}$.

\subsection{Morphology}

In Fig. 4a and b, the raw fibres have become narrow fibrils, with a reticular structure, after the chemical-purified treatment. This indicates that the purification process and bleaching did not provoke the breaking of the cellulose chains. In Fig. 4b, the release of cellulose microfibers can be clearly seen. Fig. 4c and d show the CNC samples. In Fig 4c, a drop of the colloidal suspension was put on the carbon tape and left to dry at room temperature. After covering with gold, the samples were observed and aggregations of small entities were identified. CNCs which are freeze dried appear as an aggregation of irregular 


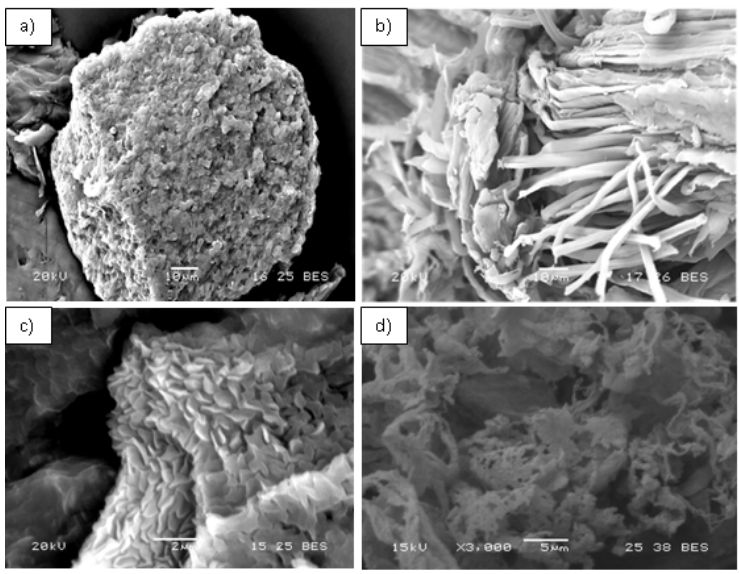

Figure 4: Micrographs of pineapple peels residues PP 1000x (a), TPP6 1000x (b), colloidal suspension CNC30 4000x (c) and freezedried CNC30 3000x (d)

rod-like assemblies of CNCs. However, individual NPs cannot be distinguished, as they are far too small for the resolution of the SEM method, which has a limit of around $30 \mathrm{~nm}$. This was also seen with CNCs extracted from sweet potatoes residues (Lu et al., 2013).

\section{Conclusions}

The purification process is important in the treatment of wastes for cellulose extraction, since pigments, waxes, hemicellulose and lignin are effectively extracted from the residues, while cellulose is not removed. The best conditions for extraction include a $6 \mathrm{~h}$ bleaching process. The time of bleaching was shown to be important for the purification of cellulose, and this was reflected by the composition, the physical properties and FTIR spectra. Indeed, the pineapple peel that was bleached for 6 hours had lower hemicellulose and lignin contents, and the CNCs produced from TPP6 (6 h) were marginally more crystalline than those produced with TPP4 (4h). In terms of hydrolysis of the extracted cellulose, the time used was not shown to be important, and 30 minutes was shown to be effective in the hydrolysis process. Even with low yields, the cellulose extracted had ca. $80 \%$ purity. Pineapple peel was shown to be a suitable cellulose source for the extraction of CNC.

\section{Acknowledgements}

Authors acknowledge financing support by the European Regional Development Fund (ERDF) through the Programa Operacional Factores de Competitividade - COMPETE, by Portuguese funds through FCT, in the framework of the project PEst-C/SAU/LA0002/2013 and Multirefinery POCI-01-0145-FEDER016403. Ana Raquel Madureira acknowledges FCT for the postdoctoral scholarship SFRH/BPD/71391/2010. Robert Pullar acknowledges the support of FCT grant SFRH/BPD/97115/2013.

\section{References}

Alemdar, A. \& Sain, M. (2008). Isolation and characterization of nanofibers from agricultural residues - wheat straw and soy hulls. Bioresource Technology, 99(6), 1664-1671. doi:10.1016/j.biortech.2007.04.029

Aspler, J., Bouchard, J., Hamad, W., Berry, R., Beck, S., Drolet, F., \& Zou, X. (2013). Review of nanocellulosic products and their applications. In Biopolymer nanocomposites (pp. 461-508). John Wiley \& Sons, Inc. doi:10.1002/9781118609958.ch20

Browning, B. L. (1967). Methods of wood chemistry. volumes $i \&$ ii. John Wiley \& Sons.

Cherian, B. M., Leao, A. L., de Souza, S. F., Thomas, S., Pothan, L. A., \& Kottaisamy, M. (2010). Isolation of nanocellulose from pineapple leaf fibres by steam explosion. Carbohydrate Polymers, 81(3), 720-725. doi:10.1016/j.carbpol.2010.03.046

Deepa, B., Abraham, E., Cherian, B. M., Bismarck, A., Blaker, J. J., Pothan, L. A., ... Kottaisamy, M. (2011). Structure, morphology and thermal characteristics of banana nano fibers obtained by steam explosion. Bioresource Technology, 102(2), 1988-1997. doi:10.1016/j. biortech . 2010. 09.030 
Flauzino Neto, W. P., Silverio, H. A., Dantas, N. O., \& Pasquini, D. (2013). Extraction and characterization of cellulose nanocrystals from agro-industrial residue - soy hulls. Industrial Crops and Products, 42, 480 488. doi:10.1016/j.indcrop.2012.06.041

Hanaor, D., Michelazzi, M., Leonelli, C., \& Sorrell, C. C. (2012). The effects of carboxylic acids on the aqueous dispersion and electrophoretic deposition of zro2. Journal of the European Ceramic Society, 32(1), 235244. doi:10.1016/j.jeurceramsoc.2011.08. 015

Henrique, M. A., Silvério, H. A., Neto, W. P. F., \& Pasquini, D. (2013). Valorization of an agro-industrial waste, mango seed, by the extraction and characterization of its cellulose nanocrystals. Journal of Environmental Management, 121 (Supplement C), 202209. doi:https : / / doi . org / $10.1016 / \mathrm{j}$. jenvman.2013.02.054

Hu, X., Wang, J., \& Huang, H. (2013). Impacts of some macromolecules on the characteristics of hydrogels prepared from pineapple peel cellulose using ionic liquid. Cellulose, 20 (6), 2923-2933. doi:10.1007/s10570-0130075-4

Johar, N., Ahmad, I., \& Dufresne, A. (2012). Extraction, preparation and characterization of cellulose fibres and nanocrystals from rice husk. Industrial Crops and Products, 37(1), 93-99. doi:10.1016/j.indcrop.2011. 12.016

Klemm, D., Heublein, B., Fink, H.-P., \& Bohn, A. (2005). Cellulose: fascinating biopolymer and sustainable raw material. Angewandte Chemie International Edition, 44(22), 3358-3393. doi:10 . 1002 / anie . 200460587

Lin, N. \& Dufresne, A. (2014). Nanocellulose in biomedicine: current status and future prospect. European Polymer Journal, 59, 302-325. doi:10 . 1016 / j . eurpolymj . 2014. 07.025

Lu, H., Gui, Y., Zheng, L., \& Liu, X. (2013). Morphological, crystalline, thermal and physicochemical properties of cellulose nanocrystals obtained from sweet potato residue. Food Research International, 50(1), 121128. doi:10.1016/j.foodres.2012.10.013
Lu, P. \& Hsieh, Y.-L. (2012). Preparation and characterization of cellulose nanocrystals from rice straw. Carbohydrate Polymers, 87(1), 564-573. doi:10 . 1016/j . carbpol . 2011.08 .022

Prozil, S. O., Evtuguin, D. V., Silva, A. M. S., \& Lopes, L. P. C. (2014). Structural characterization of lignin from grape stalks (vitis vinifera 1.) Journal of Agricultural and Food Chemistry, 62(24), 5420-5428. doi:10. 1021/jf502267s

Qiu, X. \& Hu, S. (2013). "Smart" Materials Based on Cellulose: A Review of the Preparations, Properties, and Applications. Materials, 6(3), 738-781. doi:10. $3390 / \mathrm{ma} 6030738$

Raji, Y. O., Jibril, M., Misau, I. M., \& Danjuma, B. Y. (2012). Production of vinegar from pineapple peel. International Journal of Advanced Scientific Research and Technology, 3(2), 656-666. Retrieved from http : / / www . academia . edu / 2080752 / PRODUCTION_OF_VINEGAR_ FROM_PINEAPPLE_PEEL

Sheltami, R. M., Abdullah, I., Ahmad, I., Dufresne, A., \& Kargarzadeh, H. (2012). Extraction of cellulose nanocrystals from mengkuang leaves (pandanus tectorius). Carbohydrate Polymers, 88(2), 772-779. doi:10.1016/j.carbpol.2012.01.062

Sun, X. F., Xu, F., Sun, R. C., Fowler, P., \& Baird, M. S. (2005). Characteristics of degraded cellulose obtained from steamexploded wheat straw. Carbohydrate Research, 340(1), 97-106. doi:10 . 1016/j . carres.2004.10.022

Thirawan, B., Karnnasuta, S., \& Srinorakutara, T. (2017). Agricultural wastes potential (pineapple crown, durian peel and sugarcane leaves) on reducing sugar production by using sulfuric acid pretreatment following enzymatic hydrolysis. Asia-Pacific Journal of Science and Technology, 19(3), 361-370. 